2006-1103: PHYSICAL PROPERTIES AND PROBLEM SOLVING IN

ENGINEERING: BROADENING THE EFFECTIVENESS OF TRADITIONAL ENGINEERING COURSES

Keith Bowman, Purdue University 
2006-1103: PHYSICAL PROPERTIES AND PROBLEM SOLVING IN ENGINEERING: BROADENING THE EFFECTIVENESS OF TRADITIONAL ENGINEERING COURSES 


\title{
PHYSICAL PROPERTIES AND PROBLEM SOLVING IN ENGINEERING: BROADENING THE EFFECTIVENESS OF TRADITIONAL ENGINEERING COURSES
}

\begin{abstract}
The continuity of courses related to mechanics and mechanical behavior of materials is based on a sequence that often includes an introduction of forces in a physics course based on mechanics, followed by a course on statics (and dynamics), a course on mechanics (or strength) of materials and then a course in mechanical behavior of materials. For students in materials engineering the course on mechanical behavior of materials takes place during undergraduate studies, for students in other engineering disciplines this course may be taken as a senior elective or in graduate school. The foundations leading to this upper level coursework have remained essentially unchanged for the last thirty to forty years. Although efforts have been made to evaluate and improve courses in statics, mechanics and mechanical behavior or materials, the coordination of these pieces at most universities is often nonexistent. This paper is intended to offer perspective on the continuity of this theme and the potential for broadening the foundation of this sequence to include mathematical and computational treatments throughout the curriculum that complement the math we require of undergraduate engineers. At the same time, the opportunities to introduce a broader range of tensor properties and introductory design concepts can coexist. Such an alternative path has been proposed as part of the new Multidisciplinary Engineering (MDE) program at Purdue University and preliminary discussion of progress in its implementation will be described.
\end{abstract}

\section{Introduction: The Multidisciplinary Engineering Curriculum}

The reason for initiating this new course at Purdue is based on fulfilling the needs for students in the new Multidisciplinary Engineering (MDE) located in the new Purdue School of Engineering Education (ENE), which was founded in 2004. The ENE program is Purdue's answer to a need to better understand the learning and teaching of engineering. ${ }^{1}$ The MDE program is intended to build upon the success of the Purdue Interdisciplinary Engineering (IDE) program that has enabled students to earn a degree at the interface between different engineering disciplines or engineering and other disciplines by providing a common multidisciplinary foundation for students who will then pursue a individually tailored upper level program of study to earn a 
Bachelor of Science in Engineering. The flexibility offered by the MDE program will enable responsiveness to emerging technologies that lie between traditional disciplines. For this program to be successful foundational coursework that provides problem solving context while substituting for existing engineering courses such as statics and dynamics as well as physics content such as electricity and optics that have historically required mostly beginning-college math skills for problems solving. The first MDE course (MDE 1) will be developed to present physical properties of matter as they interact within engineering systems and is entitled Physical Properties in Engineering Systems. The course includes discussions of all classes of properties - including electrical, magnetic, optical, thermal and mechanical - presented through matrix and tensor mathematics to reinforce the programming or math tool skills learned at the freshman and sophomore level. The expectations for this course include providing a supportive environment for the independent and diverse students who choose to pursue non-traditional degree paths and a broad engineering foundation for the widest possible range of study within engineering and science.

\section{Building on the Science, Mathematics and Computational Background of Students}

Although statics and dynamics are not required for all engineering disciplines (e.g. chemical engineering and electrical engineering), it is the course that faculty in mechanical engineering, civil engineering, and many other fields identify as the first experience for students to understand the ability to engage in engineering problem solving. In the MDE curriculum the MDE 1 course is targeted to contain just enough problem-solving content from statics, dynamics and introductory mechanics, but also some content related to electrical, thermal, magnetic and optical properties of materials. The test we will employ in terms of satisfying the just enough condition is to fulfill the expectations required to enter a materials science and engineering (MSE) based mechanical properties of materials course of the type often taken by undergraduate MSE students or beginning graduate students in mechanical engineering or to take a mechanic engineeringbased course in materials selection for mechanical design. Typical textbooks for the MSE course in mechanical behavior of materials include those by Dowling, ${ }^{2}$ Hertzberg, ${ }^{3}$ Courtney, ${ }^{4}$ Dieter, ${ }^{5}$ Green $^{6}$ and Bowman. ${ }^{7}$ The premier book on materials selection is the one by Ashby. ${ }^{8}$ 
The challenges inherent to the teaching of foundational engineering courses are probably most strongly demonstrated by the efforts made to address students understanding of Newtonian mechanics and statics described by Steif and Dantzler (2005). ${ }^{9}$ These authors accurately indicate the prevalence of commentary from faculty teaching courses that follow statics in believing that basic statics content of free-body diagrams, equilibrium and friction is not learned well by students. In some ways this is likely complementary to many teaching statics who believe that the foundations taught in the college level physics class of mechanics are not learned well. The very low expectations are perhaps the reason that a typical topical list like that given in Table 1 is often contained in both the standard college physics-based mechanics class and the classic engineering statics/dynamics class. This content list normally comprises between one half and two thirds of the lecture content for both classes. The possibility to streamline a curriculum by combining some of this content has been approached by others, including Bruck and coworkers $^{10}$, but these efforts are typically part of revising existing curricula as opposed to part of developing a new curriculum for a multidisciplinary program.

Table 1

Overlap Between Physics-based Mechanics and Statics/Dynamics

\begin{tabular}{|l|l|}
\hline Newton's Laws & Friction \\
\hline Particle Equilibrium & Resultants of Forces \\
\hline Free Body Diagrams & Center of Mass \\
\hline Moment about a Point or Line & Moment of Inertia \\
\hline Static Equilibrium & Particle Kinematics \\
\hline
\end{tabular}

The striking degree of overlap between these two classes was the first issue addressed in developing the content for the first offering of MDE 1. To evaluate the background of the students and understand the context for the coursework that must bridge the science perspective established in the physics mechanics background of the students the text, lecture and exam content have been evaluated in detail. The current offerings of the Purdue course Physics 152 consist of a lecture and laboratory course that uses the Tipler and Mosca text. ${ }^{11}$ The course corresponds well to the Tipler and Mosca course in that a large number of examples are employed that have a strong engineering flavor in terms of the examples employed and the nature of the descriptions., although the physics perspective is still evident. The level of math 
employed in this class and also for most similar texts employs math at a level concurrent with the normal corequisite of Calculus II.

Although the list of the topics given in Table 1 shows considerable overlap, the complexity of the problems and the style of statics or statics/dynamics classes have a very strong engineering context. It is very common for the class to strongly emphasize engineering traditions such as engineering paper and a layout of homeworks similar to that shown in Table 2.

Table 2

Homework Problem Solving Approach

1. Write the given conditions

2. Write the results desired

3. Draw essential diagrams (free-body diagrams)

4. Develop equations

5. Obtain solution

6. Check solution (Units)

The statics courses, and even moreso the follow-on mechanics (or strength) of materials classes, rarely raise the level of mathematics much above that used in the physics-based mechanics course. In fact, in many cases there is a continuous reduction in actual mathematics expectation even though more advanced pre- and corequisites are required.

At Purdue and many other engineering programs the teaching of basic programming and math tools in a computer course is considered an absolutely essential component of the curriculum. Attempts to make changes in computational skills courses are potentially one of the most controversial efforts that can be engaged in an engineering college. It is then surprising that the foundational engineering courses that follow the first year program infrequently require the use of the computer tools that the students were required to learn. Accordingly, the statics/dynamics and mechanics of materials classes taught in most large engineering programs do not avail themselves of the matrix mathematics and visualization tools and functions that are some of the most empowering aspects of math software such as Matlab ${ }^{\mathrm{tm}}$, Mathcad ${ }^{\mathrm{tm}}$ and Mathematica. 


\section{Goals and Objectives for MDE 1}

The MDE 1 class is being developed to demonstrate a foundational engineering course that could bridge into most individual or multidisciplinary pathways that engineering students could encounter. It is a departure from the mechanics-oriented curricula of mechanical engineering, aeronautical and astronautical engineering, industrial engineering and civil engineering and perhaps most suitable within curricula of biomedical engineering, materials engineering, environmental engineering and multidisciplinary curricula that include some mechanics expectations and could potentially provide a broader engineering perspective to engineering students in electrical engineering and chemical engineering programs.

The first offering of the MDE 1 class is being team taught as lecture course that includes team and collaborative learning activities, homeworks with required solutions in Mathcad ${ }^{\mathrm{tm}}$ or similar math software, mathematics concurrent with the corequisite linear algebra course. It is being taught by two faculty members, one with a mechanical behavior of materials background and use of computer tools in materials science and one engaged in computational materials science from a physics perspective. Every opportunity to emphasize matrix and tensor-based solutions will be used to develop facility with computational tools in the context of the physics, mathematics and engineering. The principal course objectives are

1. To provide an introduction to the quantitative tools essential to engineering in a problem-solving environment

2. To provide a context for considering the interactions and synergistic relations between properties in engineering systems

The proposed course outline for the first offering is given in Table 3. Because there is no text for the course the first two years of offerings will be used to generate an extensive set of course notes and examples based on the best available demonstrations of a computational context for foundational engineering courses. In cooperation with colleagues from the ENE curriculum a series of integrated and evaluated on-line modules are under development. 


\section{Table 3}

Course Schedule for MDE 1

\begin{tabular}{|c|c|c|}
\hline TOPICS & Group Act. & \\
\hline Introduction & ART & \\
\hline Computation/coordinates & & HW1 \\
\hline \multicolumn{3}{|l|}{ Review PHYS152 } \\
\hline Review PHYS152 & & HW2 \\
\hline Free Body Diagrams & COFFEE CUP & \\
\hline Statics & & HW3 \\
\hline Statics & & Quiz 1 \\
\hline Statics - 3D & PRES. TOPICS & HW4 \\
\hline \multicolumn{3}{|l|}{ Dynamics - Equations of motion } \\
\hline Dynamics- Conservation Laws & & HW5 \\
\hline \multicolumn{3}{|l|}{ Harmonic motion } \\
\hline Sound Waves & & HW6 \\
\hline Sound Waves & & Quiz 2 \\
\hline Mechanics \& Dynamics of Cells & CELL MODEL & HW7 \\
\hline \multicolumn{3}{|l|}{ Numerical solutions to motion } \\
\hline Molecular Dynamics & & HW8 \\
\hline \multicolumn{3}{|l|}{ Exam Review } \\
\hline \multicolumn{3}{|l|}{ Midterm Exam } \\
\hline BREAK & BREAK & BREAK \\
\hline BREAK & BREAK & BREAK \\
\hline \multicolumn{3}{|l|}{ Stress and Strain } \\
\hline Mechanical Processes & & HW9 \\
\hline Coord. Trans. Stress \& Strain & & Quiz 3 \\
\hline Second Rank Tensors & & HW10 \\
\hline Elasticity and Anisotropy & $\begin{array}{l}\text { TENSOR } \\
\text { DESIGN }\end{array}$ & \\
\hline Thermal and Electrical Conductivity & & HW11 \\
\hline Fluid Flow & & Quiz 4 \\
\hline Fluid Flow & & HW12 \\
\hline \multicolumn{3}{|l|}{ Diffusion } \\
\hline Diffusion across Cell Membranes & & HW13 \\
\hline \multicolumn{3}{|l|}{ Presentations } \\
\hline Review & & \\
\hline
\end{tabular}

The MDE 1 course will also be evaluated by extensive consideration of student work and performance and will employ extensive discussions with the students of how well they feel the 
experience in MDE 1 has prepared them for their future studies. After several years of offerings the students who have further proceeded through their study programs will be contacted to assess the success of the class in enabling them to perform their particular pathway through the MDE degree program. Their inputs will be used to refine and improve the course in a fully reciprocating system of evaluation and retooling for the MDE course. Later offerings of the course will potentially include students from biomedical engineering and materials engineering.

\section{Acknowledgments}

This Purdue MDE program is supported by a grant from the National Science Foundation, 0431906-EEC. Alejandro Strachan of the Purdue School of Materials Engineering is co-teaching this course and has had invaluable input on the direction and philosophy for this class.

\section{References}

1. K. Haghighi, "Quiet No Longer: Birth of a New Discipline," Guest Editorial, J. Eng. Education, V. 94, [4] 351$353(2005)$.

2. N. E. Dowling, Mechanical Behavior of Materials : Engineering Methods for Deformation, Fracture, and Fatigue $2^{\text {nd }}$ Edition, Prentice Hall, 1998.

3. R. W. Hertzberg, Deformation and Fracture Mechanics of Engineering Materials, 4th Ed., Wiley, 1996.

4. T. H. Courtney, Mechanical Behavior of Materials, McGraw-Hill, 1990.

5. G. E. Dieter, Mechanical Metallurgy, 3rd. Ed., McGraw-Hill, 1986.

6. D. J. Green, An Introduction to the Mechanical Properties of Ceramics, Cambridge, 1998.

7. K. J. Bowman, An Introduction to Mechanical Behavior of Materials, Wiley, 2004.

8. M. F. Ashby, Materials Selection in Mechanical Design, $3^{\text {rd }}$ Edition, Butterworth-Heinemann, 2005.

9. P. S. Steif and J. A. Dantzler, "A Statics Concept Inventory: Development and Psychometric Analysis", J. Eng. Education, V. 94, [4] 364-371 (2005).

10. H. A. Bruck, D. K. Anand, W. L. Fourney, P.C. Chang, and J. W. Dally, "Development of an Integrated Statics and Strength of Materials Curriculum with an Emphasis on Design", ASEE Proceedings 1999, Paper 2566,

11. P. A. Tipler and G. Mosca, Physics for Scientists and Engineers, Vol. 1 and 2, $5^{\text {th }}$ Ed., W. H. Freeman and Co., 2004. 